\title{
ВИДЕОУРОК КАК ПРОИЗВОДНАЯ КЛАССИЧЕСКОГО УРОКА
}

\section{Трондина С.О.}

БФУ им. И. Канта, г. Калининград, Российская Федерация

В данной статье рассмотрень средства обучения, в частности аудиовизуальные. К аудиовизуальным средствам обучения относится видеоурок - современная форма урока. В статье рассмотрень преимущества и недостатки видеоролика.

Ключевые слова: визуальные средства обучения; аудиовизуальные средства обучения; видеоурок; атрибуты видеоурока.

\section{VIDEO TUTORIAL AS A DERIVATIVE OF THE CLASSIC LESSON}

\section{Trondina S.O.}

Immanuel Kant Baltic Federal University, Kaliningrad, Russian Federation

This article discusses the means of training, in particular audiovisual. The audiovisual teaching tools include a video tutorial-a modern form of lesson. The article discusses the advantages and disadvantages of the video.

Keywords: visual learning tools; audio-visual learning tools; video lesson; the attributes of the video.

Модернизация современной системы образования акцентирует внимание на быстром внедрении компьютеров во все сферы жизни, что влечет необходимость для поэтапного перехода к новому уровню и качеству обучения, к внедрению в учебный процесс новых дидактических средств обучения. В числе приоритетных направлений 
для совершенствования дидактических средств рассматривается визуализация [1]. Очевидно, что визуальные средства играют важнейшую роль в процессе обучения, они облегчают взаимодействие двух сигнальных систем, первую систему основывают сигналы, непосредственно отражающие действительность в форме ощущений и восприятий, а в основу второй входят речевые сигналы. Эти сигнальные системы тесно функционируют друг с другом, поэтому для человека слова приобретают способность сигнализации о явлениях действительности. В учебном процессе явления действительности демонстрируются не только посредсвом естественных образцов, но и при помощи карт, схем, моделей, то есть визуальными средствами обобщающего характера. Но, как показывает практика, не всегда учитель имеет в распоряжении естественные образцы, и тогда ему на помощь приходят средства, заменяющие их, а это чаще всего изображения, модели, графики, диаграммы. Такие средства позволят представить объект во всем его многообразии, в увеличенном или уменьшенном виде, в разрезе, проследить причинно-следственную связь, различные зависимости, а также показать действительность при помощи визуальных знаков.

Визуальные средства обучения испытывают влияние новейших достижений техники. Доля аудиальных средств в процессе обучения все время увеличивается. Технический прогресс и связанное с ним развитие стереофонии в настоящий момент позволяют применять в работе с учащимися средства, имеющие дидактические достоинства.

Аудиовизуальные средства в школе формируют у учащихся определенные впечатления, наблюдения и представления. Они оказывают воздействие сразу на два анализатора - зрительный и слуховой. Это и определяет их привлекательность. К числу аудиовизуальных средств можно отнести звуковой фильм и телевидение.

Учебный фильм играет в учебном процессе важную роль. Посредством подвижного образа и звука он закрепляет представление об определенных явлениях, объектах, процессах, а также позволяет показать все это несколько раз, в разное время и неизменной форме. Учебный звуковой фильм создает одинаковые условия для про- 
смотра и прослушивания. Это значит, что он знакомит учащихся с новым материалом, также применяется для закрепления, контроля знаний, и даже оценки результатов работы.

Форма видеоурока повторяет практически все догматические принципы обычного урока, и только в форме заключается существенная разница. Наибольший прогресс изменения формы классического урока в видеоурок замечен в самообразовании. Сегодня сеть Интернет является источником различного рода видеоуроков. Такие сайты как http://klubknig.ru/videouroki// предлагают большое количество видеоуроков по всевозможным темам, от садоводства до изучения учебных предметов, от аэробики до уроков по осенней рыбалке.

Анализ школьной практики позволяет нам заметить, что видеоурок пока не достаточно активно используется в обучении, но пользуется огромной популярностью по следующим причинам:

- у учебный процесс проходит в естественной форме для ученика, сидя перед компьютером/планшетом/телефоном в комфортной обстановке, он повторяет действия за автором, приобретая всё новые умения и навыки;

- видеоурок мобилен, так как его можно смотреть как дома, в школе, так и на улице, в кафе и так далее;

- один видеоурок или весь видеокурс можно изучать любое количество раз.

Однако внедрение видеоурока в школьную практику имеет весьма существенные трудности. Это не оборудование или наличие материала, а, прежде всего, контроль над получением знаний школьника, который проводится самостоятельно, так как обучающийся сам выбирает время занятий, и отслеживает эффективность приобретенных знаний.

Выделим ряд атрибутов видеоурока:

1) процесс передачи навыков и умений (знаний);

2) роль учителя (в данном случае закадрового голоса);

3) план передачи знаний (связанность одного урока с другим);

4) самоконтроль. 
Учитывая все выше сказанное, можно заметить, что видеоурок производная классического урока с ярко выраженной современной формой.

Сегодня учитель имеет в распоряжении многочисленные возможности применения в процессе обучения цифровых образовательных ресурсов - это информация из сети Интернет, электронные учебники, словари и справочники, презентации, программы, различные виды коммуникации - чаты, форумы, блоги, электронная почта, телеконференции, вебинары и др. Благодаря этому, актуализируется содержание обучения, происходит быстрый обмен информацией между участниками образовательного процесса [1]. Однако не все готовые материалы соответствуют теме занятия, при этом учебный материал может быть скудным или же полнее, чем необходимо на данном этапе обучения. По этим причинам учителю, взявшему видеоролик, придется подстроиться под имеющуюся версию. Поэтому, зная особенности учеников, учебный материал, который необходимо изложить, адекватнее разрабатывать самому учителю. Видеоматериал можно закрепить или повторить в любое время и в любом месте, не говоря уже о том, что просмотр может осуществляться даже со смартфона.

\section{Список литературы}

1. Алексеева Е.Е. К вопросу развития компонентов информационного образования учителя определяющих их готовность к реализации ФГОС// Современные исследования социальных проблем (электронный научный журнал). 2018. Т. 9. № 5. С. 6-18.

2. Полат Е.С., Бухаркина М.Ю., Моисеева М.В., Петров А.Е. Новые педагогические и информационные технологии в системе образования / под ред. Полат Е. С. М. Изд. центр «Академия», 2010. 272 с.

3. Дидактические средства [Электронный ресурс]. Сайт педагога-ислледователя. URL: http://si-sv.com/publ/1/14-1-0-214

4. Видеоурок - современная форма образования [Электронный ресурс]. Scholar.su. URL: https://scholar.su/content/videourok-sovremennayaforma-samoobrazovaniya 


\section{References}

1. Alekseeva E.E. K voprosu razvitiya komponentov informatsionnogo obrazovaniya uchitelya opredelyayushchikh ikh gotovnost' $\mathrm{k}$ realizatsii FGOS// Sovremennye issledovaniya sotsial'nykh problem (elektronnyy nauchnyy zhurnal). 2018. T. 9. № 5. S. 6-18.

2. Polat E.S., Bukharkina M.Yu., Moiseeva M.V., Petrov A.E. Novye pedagogicheskie i informatsionnye tekhnologii v sisteme obrazovaniya / pod red. Polat E. S. M. Izd. tsentr «Akademiya», 2010. 272 s.

3. Didakticheskie sredstva [Elektronnyy resurs]. Sayt pedagoga-islledovatelya. URL: http://si-sv.com/publ/1/14-1-0-214

4. Videourok - sovremennaya forma obrazovaniya [Elektronnyy resurs]. Scholar.su. URL: https://scholar.su/content/videourok-sovremennaya-forma-samoobrazovaniya 